\title{
THE PERSONALITY OF A SAFETY MANAGER
}

The main aim of the contribution is to provide a detailed review of the role of the safety manager, and to describe the specific demands of his work when enforcing safety in an institution. Attention is given both to the personal characteristics and professional qualifications necessary for performance of his work, which can be complex but also thankless, and also the psychological influences. From a practical standpoint the authors define the essential personal characteristics for the position of a safety manager, and consider ways and options on how to best select a safety manager when filling this important managerial post in an institution, from the IT environment in businesses and state entities, to professional security organisations.

\section{Work specificity of safety manager}

Safety can be easily defined as a permanent activity ensuring continuity of a certain key process. The process can be, for example, maintaining the existence of the State (and the State's security), securing of income from business activities (for example Business Continuity Planning - BCP), or just human life (health and safety at work and in the private life).

The duty of a safety manager can be described by the following specifications, which at the same time require the possession of specific knowledge, skills, experience and personal characteristics, which are crucial for the successful performance of his duties:

- The majority of staff in a company subjectively view his work as redundant, restrictive or controlling, and very rarely perceive his position positively. Safety must always be enforced (via rules, directives, laws, technological restrictions, access rights, tests, controls, rehearsals etc.), which is in contradiction to the more comfortable working environment people have been used to until now. Where rules are breached, penalties are imposed. On the other hand safety can be enforced in an intelligent human, and decent manner, and such enforcement methods are usually successful. The crucial role is the personality of a safety manager (and bodies directly superior and inferior to him in the organisational structure).

- Safety today is technologically very complex, and requires expertise in a number of fields. At the same time a harmony between the technological, administration, organisational and personnel solutions of safety is a must. Safety must not be solved only by technocratic tools otherwise it can fail relatively quickly. The safety manager must therefore be much more than merely a specialist focused on a narrow field.

- Safety has a preventative character. Safety analysis or audits, prognosis or general trends are used to develop arrangements to eliminate potential risks. Safety cannot be solved without tech- nological solutions, which can be costly, but from the point of view of management, shareholders or owners no direct benefit from the investments is often seen. Well performed safety is not obvious from the outside. Safety projects are largely infrastructure in character (affecting the whole company), and it is hard to justify them on purely economic grounds. Usually no exact return of the investment can be determined (Return On Investment - ROI or by using a different economic method). More often expenditure is justified in order to protect existing investments, information or company assets. What can happen if this is not carried out ...? What extent of loss will a company suffer if email does not work for a number of days? The justifications by the safety manager must be very sensitive and diplomatic, and the manager must be fully respected and enjoy trust.

- The safety solution must be complex and systematic. Safety is as vulnerable as its weakest component. The target of attack (or other safety incident) is usually known, and can be traced under certain circumstances. However there is a number of ways an attack can be performed, and the level of uncertainty is very high. The safety manager must therefore have a good understanding of past safety incidents. Experience and knowledge from different types of organisation is very valuable as is the use of experience from countries different than where the safety manager is employed. For very obvious reasons not many institutions publicise their safety incidents and the resulting impacts on the institution. Apart from the knowledge, experience and analytical skills the safety manager must be gifted by prescience, professional intuition, imagination and creativity in order to be able to place himself into a mind of a potential attacker, or to be able to uncover hidden threats (technical, natural etc.), which have not yet happened. Apart from professional experience there must be also a certain professional suspiciousness, with the purpose of uncovering weaknesses. Suspicion must never slip to personal attack, and presumption of innocence must be respected. Hypothesis of suspicion must be objectively verified before any opinion is expressed publicly.

\footnotetext{
* Roman Rak ${ }^{1}$, Marián Mesároš² ${ }^{2}$ Viktor Porada ${ }^{3}$

${ }^{1}$ Czech Telecom a.s., Olšanská 5, CZ-130 00 Praha 3, Czech Republic, E-mail: Roman.Rak@ct.cz

${ }^{2}$ Faculty of Special Engineering, University of Žilina, Kukučínova 17, Košice, Slovakia, E-mail: fsi-ke@fsi.utc.sk

${ }^{3}$ Police Academy of the Czech Republic, Lhotecká 559/7, P.O.Box 54, 14301 Praha 4, Czech Republic, E-mail: Porada@polac.cz
} 
- The Safety manager is alone in his position. He must be able to communicate well and effectively with both his subordinates, members of senior staff, and suppliers of different technologies, and he is permanently solving conflict and sensitive situations. A number of activities are carried out with a certain degree of confidentiality. Great deal of responsibility is put on the safety manager and sometimes he even does not have sufficient means to carry out safety arrangements to the extent the situation, the theory or his own ideas demand in order to bear the responsibility. A level of responsibility with regard to a risk may not necessarily correspond with rights or means which are available to a safety manager. The safety manager is expected to be highly loyal, reliable and confidential. A situation may occur where he will be influenced by the top management in contradiction to his mission. Frequently top management can represent a high risk for an entity (i.e. the loss or theft of sensitive information), because they cannot or will not comply with some basic principles of safety. Additionally top management is sometimes even deliberately trying to circumvent controls due to a number of different reasons (the feeling of power and invulnerability, or in some extreme cases even collaborating with third parties, or deliberate abusing of own power for personal gain). If this is the case for somebody naturally the safety manager will be in his way and will become his enemy. To bear the burden of some findings and not to share them with a third party (including a partner, family, friends) is no trivial task for the safety manager either. In some extreme cases (state security bodies of operative character) safety managers are required to hide their civil identity from colleagues, friends or acquaintances, and at the same time are made to use a legend of a different employer and profession, and they even have to conceal their real job from their families. Professional deception and a number of means to support the so called "cover-up" are used. It is very demanding for psyche of a safety manager to be able to live life "two ways".

- The globalised world, the environment and the institution where safety is carried out, are currently very dynamic, often uncoordinated, uncertain and chaotic. With a number of changes undergoing (competitive, strategic, organisational, personnel etc.) which are accompanied also by negative emotions of employees, labour fluctuation is frequently seen. Any instability reflects on safety arrangements negatively, and it is absolutely crucial to be able to react in time, in an adequate manner, and optimally to comply with current trends and situations.

- The safety manager must be prepared to perform his duty in all circumstances. He can himself become the object somebody else's interest, therefore a strong personality and integrity is demanded. His personal characteristics, behaviour and both professional and private history must not make him vulnerable and governable. No potential reasons should exist so he can either be blackmailed or compromised. The safety manager must be ready to

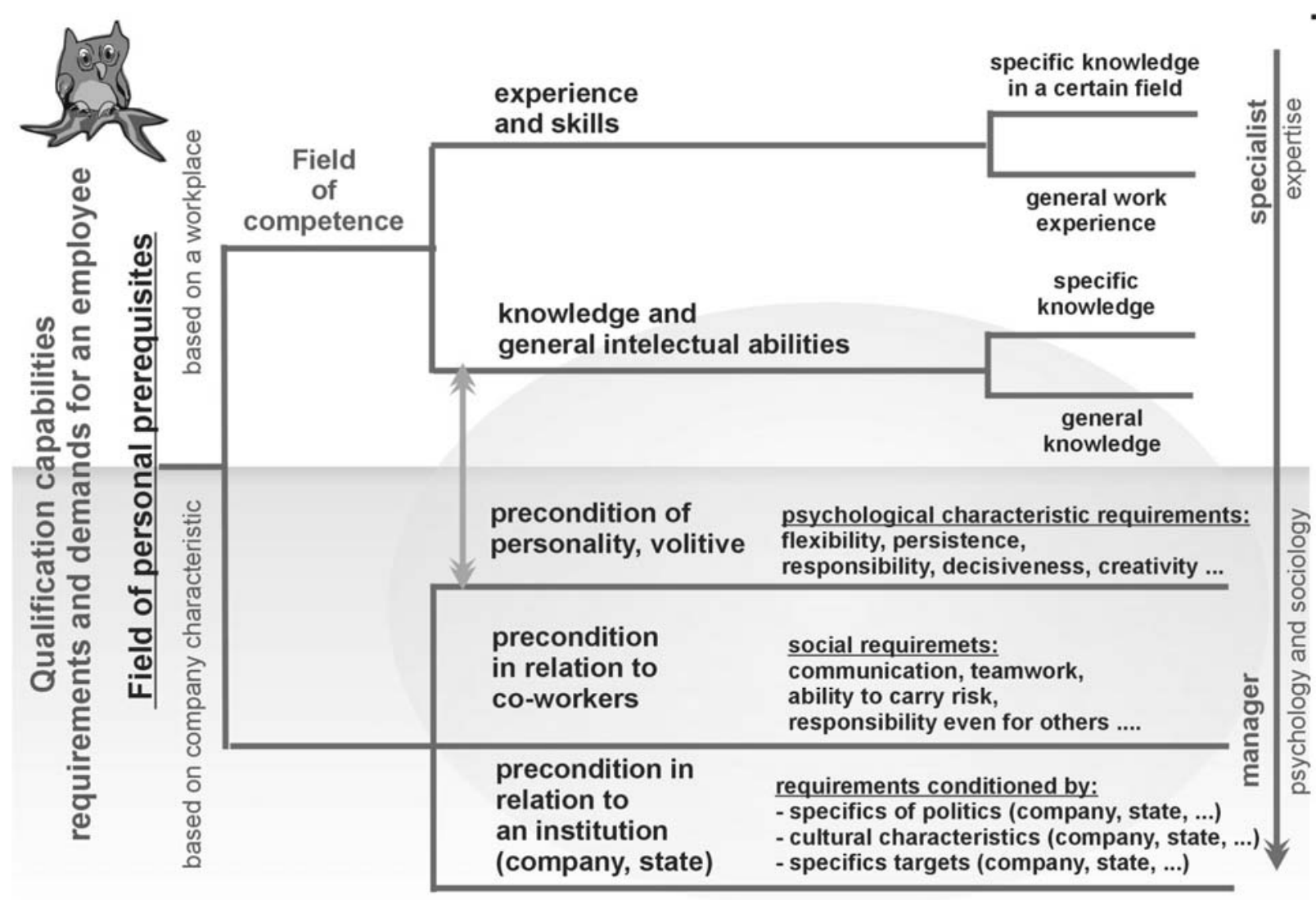

Fig. 1. Requirements and demands on (safety) manager. 
be resistant to large number of personal attacks due to different reasons, and deal with them in a sensible way. At the same time he has to take responsibility for number of risks. The safety manager should be able to learn the professional philosophy that either he is checking or testing somebody/something, or he himself is the subject of control. For that very reason he has to be able to work transparently with regard to superior controlling bodies.

- Unclear Authority. The safety manager frequently does not have clearly defined authorities in his work, resulting in professional clashes inside the company which have to be sensitively and sensibly solved. The boundary between IT security, personal and general security and mainly between internal audit bodies, risk management etc. is not always clearly drawn. Conflicts may arise in companies where more professional players happen to work on safety without rules being determined which has a negative impact on safety globally. Internal frays occur in organisations at the expense of meeting the primary task - secure safety.

\section{The Qualification requirements and demands on a safety manager}

For better understanding of requirements and demands on a safety manager it is useful to divide the qualification requirements into several logical categories, as shown in Figure 1. The authors are following the theoretical, basic qualification capabilities of any employee, who then will be a subject of discussion and comparison with specification of the safety manager work.

\subsection{Field of competence}

When discussing the work of a safety manager we frequently come across a question as to what extent (expressed in percentage) this is a managerial position or the position of a specialist. In literature [11] we can find a ratio of 60:40, i.e., managerial activities constitute $60 \%$. We have the opinion that such a ratio cannot clearly be set, although the title of safety manager encourages us to think that it is mainly managerial work (i.e. "at least 50\%"). However, more important is the current position of a safety manager in an institution, his place in the organisation, what his responsibilities authorities are, how many direct subordinates he has in his safety department, how he cooperates with the company management or the company staff. Depending on the various models described above of the position of the safety manager in organisational structure, and depending on his duties it is obvious that in extreme cases the safety manager can be from an IT specialist background (the model of minimal technological safety) with minimal managerial activity, to managerial positions (the model of extensive institutional safety), where almost $100 \%$ of the activities of the manager is focused on cooperation and coordination between different experts, employees, management and shareholders of the company.

In this contribution we will not analyse the required experiences and skills, knowledge of the safety manager - the requirements derive from the institution itself. In the field of IT, it can be for example knowledge of different network protocols, coding algorithms and technologies, firewalls, databases etc. Generally applied it can also include security of buildings, different procedures when protecting data from defensive (competitive) intelligence, personal security etc.

\subsection{The field of personal prerequisites}

Human personality is complex from the psychological point of view. Personality can either have or not have strong characteristics. Psychology of personality is therefore focused on the analysis of the whole, and on determination of the characteristics.

When analysing the personality of a particular human being, we usually seek an answer to the question of what he is like. We try to find his psychological characteristics, where he is similar and where he is different from the other people, what he can do, and what and how he achieves.

The term personality comprehends that our behaviour and cognition in its various shapes and sizes, has a whole cohesive character and nature. In any moment of happening "I" is active inside of us into which the results of our activities are integrated. That is how personality guarantees continuity of cognition over time.

The term personality therefore reflects the whole, integrated character of psychological activity. The second crucial feature is uniqueness. Personality of a human being is always unique. From the psychological point of view there cannot be two people with identical personalities. Whilst we know doubles in terms of physical similarity occur, from the psychological point of view unity of mental parameters is ruled out. In practice it means that nobody thinks exactly in the same way as "I". Psychological understanding of uniqueness clarifies the following known assertion that each person in some respects:

- is the same as everybody else

- is the same as some of the others and at the same time in some respects ...

- is different from everyone else.

The whole set-up of mental activity is in this sense unique and unrepeatable.

Personality has a number of definitions in psychology. Through different terminology the base of the following term is explained: personality is understood to be relatively stable composition of biological, psychological and sociological characteristics joined in a unique process of mental activity, which each of us experiences as our own "I".

For an evaluator or external observer our personality represents an individual and unique "mix" of common and perhaps less common, abilities and characteristics. Now we come to the question what the personality of each human being consists of. Professionally speaking it is an issue of structure or composition of personality. 
The issue of a structure of personality can be explained by a simple example. It is known that different people behave in the same situation in different ways. For example following criticism from a boss some might respond by rejecting the reprimand, some might blame colleagues for the mistakes, and others might use family members as an outlet. The differences in their monitored behaviour can be explained by their different personalities, i.e. the difference in the structure and dynamics of personality.

In order to be able to understand how individuals vary, it is necessary to divide personality into components. The differences between people are caused by what components of their personalities are represented, and at the same time how strongly each component is shown. Dividing personality into partial components and their mutual relations set the basic problems of a structure of personality.

The structure of personality reflects what is from the psychological point of view permanent, and also what characteristics only express themselves in certain situations. It means that we usually judge personality according to an individual's behaviour. It is important to bear in mind that only a certain part of personality can show in each situation.

We know the impact of a situation from our own experience. Each of us can be friendly, but also cold and unpleasant. What pattern of behaviour is shown depends upon situation. To a person whom we want to attract and win favour we can be almost adorable. On the other hand, to a person we dislike and who annoys us with his presence, we can be reserved, short and irritated. The situational variability of our behaviour is natural. At the same time neutral interactions with others result in a typical behaviour from us e.g. friendly and open, or rather reserved and restrained. We talk about a disposition or characteristic which is typical for individuality. Personality structure means relatively stable characteristics of personality which are of a dispositional nature. The structure of personality creates an individual base for behaviour and experiencing, which is updated depending on the situation.

The term personality structure assumes dividing of the psychological whole, i.e. splitting the unified personality to bounded,

\begin{tabular}{|c|c|}
\hline \multicolumn{2}{|c|}{ Requirements for the position of a safety manager } \\
\hline Personality and volitional requirements for a safety manager & \\
\hline $\begin{array}{l}\text { Problems solving } \\
\text { The safety manager should show good analytical skills, healthy } \\
\text { judgement and appropriately judge all necessary circumstances: } \\
\text { - Clearly identifies the task; } \\
\text { - Demonstrates clear understanding of a problem and the relating issues; } \\
\text { - Analyses problem clearly and with necessary explanation; } \\
\text { - Is able to determine the core of a problem and key points; } \\
\text { - Considers all essential information; is able to obtain information } \\
\text { independently from different sources, is unbiased when verifying the } \\
\text { information, analyses; } \\
\text { - Healthy judgement; } \\
\text { - Shows a well organised, planned and logical approach; } \\
\text { - Is independent when solving tasks and problems. } \\
\text { Decision making } \\
\text { Shows ability to foresee, makes realistic decisions based on available } \\
\text { sources and is willing to take responsibility for his decisions: } \\
\text { - Makes decisions without necessary delay, which are clearly articulated; } \\
\text { - Decisions are supported by obtained information and facts; } \\
\text { - Foresees and considers both short and long-term impact of his deci- } \\
\text { sions; } \\
\text { - Sets priorities. } \\
\text { Creativity } \\
\text { Shows innovative approach and originality when responding to } \\
\text { a problem and is flexible when assessing progress of action: } \\
\text { - Keeps a flexible approach; } \\
\text { - Initiates alternative procedures; } \\
\text { - Willingness to accept new thoughts, action plans and decisions; } \\
\text { - Shows innovative, original or lateral thinking (using unusual relations) } \\
\text { - views issues and problems from a broader perspective, has a sense } \\
\text { of detail but does not get buried in it; } \\
\text { - is a visionary, is able to formulate strategic visions and targets in } \\
\text { given area of responsibility. }\end{array}$ & $\begin{array}{l}\text { Persistence, self-motivation and motivation of others } \\
\text { Submits solutions in a way which persuades others about acceptability } \\
\text { of the solution: } \\
\text { - Persists and does not yield in effort, when coming across to } \\
\text { resistance; } \\
\text { - Shows high level of motivation, interest and involvement in problem } \\
\text { - solving; } \\
\text { - Is able to motivate others and raise trust. } \\
\text { Coping with burden } \\
\text { Constructively reacts to frustration, able to accept criticism, keeps } \\
\text { calm and knows how to deal with multiple problems at the same time: } \\
\text { - Constructively reacts to a failure or frustration; } \\
\text { - Can cope with multiple problems at the same time; } \\
\text { - Stays calm, under control and considers coolly; } \\
\text { - Can avoid exaggerated reactions; } \\
\text { - Remains tolerant in conflict situations when facing resistance: } \\
\text { - assertive; } \\
\text { - can accept constructive criticism; } \\
\text { - effectively utilises time. } \\
\text { Integrity } \\
\text { The safety manager's career has up to now been exemplary, cannot be } \\
\text { challenged from the trust and reliability point of view. Any preconditi- } \\
\text { ons for blackmail, dependency, influence are absent: } \\
\text { - has a clean record; } \\
\text { - does not take addictive material (drugs, alcohol etc.); } \\
\text { - lack of risk dependency upon money (debt, hazardous games, ...). } \\
\text { Personal charisma } \\
\text { - is both socially and professionally recognised, or is recognised by } \\
\text { senior and middle management, by his direct colleagues. }\end{array}$ \\
\hline
\end{tabular}




\begin{tabular}{|c|c|}
\hline \multicolumn{2}{|c|}{ Requirements for the position of a safety manager } \\
\hline Pre-conditions with regard to his colleagues & \\
\hline $\begin{array}{l}\text { Communication skills } \\
\text { The safety manager is able to communicate clearly and concisely both } \\
\text { orally and in a written way, takes other's needs into consideration. } \\
\text { During the selection procedure he has to demonstrate: } \\
\text { - clear and suitable language; } \\
\text { - appropriate usage of vocabulary, stylistics and grammar; } \\
\text { - thinks before starts speaking or writing; } \\
\text { - his language makes him to be completely understood; } \\
\text { - chooses communication which fits best to a type of a receiver; } \\
\text { - is able to avoid jargon and slang; } \\
\text { - is able to communicate in complicated critical situations. } \\
\text { Interpersonal relations } \\
\text { Is open to opinions and wishes of other people and is able to } \\
\text { cooperate with them. Is tactful and diplomatic: } \\
\text { - Is able to show tact and diplomacy when dealing with other people } \\
\text { and when solving problems; } \\
\text { - Show understanding, perceptiveness to opinions and feelings of } \\
\text { other people; } \\
\text { - Is interested in impact of his words on other people; } \\
\text { - Develops work cooperation with other people. He is a team-player } \\
\text { and can also lead a team. Is able to cooperate in a team; } \\
\text { - Avoids prejudice and dogmatic opinions. }\end{array}$ & $\begin{array}{l}\text { Presentational and educational skills } \\
\text { - Presents thoughts, action plans and decisions in persuasive manner; } \\
\text { - Is able to sale himself, his team, organisational unit, a problem } \\
\text { which is a subject of a solution; } \\
\text { - Is able to use different technologies for presentation; } \\
\text { - complex and technical issues can explain clearly even to non-profes- } \\
\text { sionals; } \\
\text { - is patient; } \\
\text { - very good written skills, can create clear and concise binding } \\
\text { documents. }\end{array}$ \\
\hline
\end{tabular}

\begin{tabular}{|l|l|}
\hline \multicolumn{2}{|c|}{ Requirements for the position of a safety manager } \\
\hline Preconditions with regard to an institution \\
\hline Representing the employing institution and identification. \\
The safety manager creates a positive impression of an institution, \\
identifies with the company mission and ways it is enforced. \\
- Permanently gives positive impression; \\
- Is loyal to the institution; \\
- Is loyal to mottos, culture and the company ethic. & \\
\hline
\end{tabular}

relatively independent components. There are different opinions in psychology as to what components create a structure of personality. Individual approaches vary mainly in number and type of components identified.

The basic requirements for a safety manager (according to Figure 1) are summarised in the three tables below with the following break-down.

The requirements for a safety manager are mainly based on the mission of a company and can vary from institution to institution. Examples of entities with different requirements would be: a) a smaller company owned by a Czech owner; b) an international company, where any relation to the Czech language, culture, religion, political affiliation might be totally suppressed; c) state security bodies (requires an indifference to politics, the protection of Czech interests and the interests of coalition partners or allies) d) security bodies of political parties (which requires a positive approach and loyalty to certain politics etc.).

\section{The issue of identifying personality}

Identifying the personality of a particular person is the touchstone of psychology. It verifies the relation between reality and its psychological reflection. If we describe the personality of a person, it allows us to some degree to predict his behaviour in different situations. The more exact the description of personality the more precise the prediction of behaviour. It is mainly useful for two purposes:

1. To understand behaviour/actions which already took place (i.e. to understand inner motives of a surprising action or to allocate certain behaviour to his probable originators). In the case of safety managers it can for example help us to understand why up to now a reliable and loyal manager has committed a misconduct, or to identify who initiated an incident, who was the leader and who was only following.

2. To estimate and predict human behaviour (e.g. to select the best candidate for a managerial position etc.). 


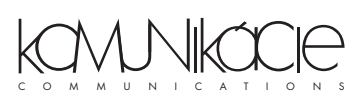

In both cases our assumptions on personality are based on observations on how individuals appear.

Rather than looking for personality characteristics and more permanent features which represents a list of general characteristics of an "ideal" manager, we regard an interactive, dynamic approach to a specific personality of manager as more appropriate. In requirements and profiles, models for professions are frequently set at unrealistic levels, often supported by empty, general terms such as reliability, flexibility, loyalty, creativity (what about if he is "creative" against the interests of the company?).

Supposing for some reason a manager loses motivation to be loyal to his employer at that moment all his original positive characteristics and abilities required at the selection process work against the employer. Additionally we have to bear in mind that loyalty and reliability is not something necessarily something permanent - they have to be fostered, strengthened towards the company. Even the most loyal employee is bribeable, it is just a question of price. The preliminary psychological examination, consisting of psychological methods and procedures used in clinical practice, provides only introductory data and information on dispositions, which have to be continuously verified and revised. Possible changes have to be monitored and evaluated - this is the purpose of forensic psychological audit.

The psychological foundation of this approach and tools leading to identifying personality, identification and understanding of standpoints, which an individual takes in real working and managing situations (mainly in conditions of increased psychological burden). It mainly concerns the standpoint of an individual towards other people (relationally important people, and through them to the reference groups and to the whole society), towards the performed work, including the conditions, under which the work is carried out (and towards the institution and its targets) and towards himself (which reflects self-reflection and self-estimation), towards situations, which he is in.

Cognitive, emotional and conative ability to act certain way is reflected in standpoints. Cognitive processes bring information/ knowledge. In emotions we experience their significance. In standpoints, which integrates cognitive and emotional aspects of psychology, we take value relationships towards objects, i.e. we allocate certain value, they either appear desirable or undesirable, good orb ad.

Anticipation is present in each standpoint - i.e. assessing assumed effect of activities. A standpoint is not just a subjective reflection of reality. It closely relates to self-reflection of a human being. We create standpoints on the base of knowledge of reality and at the same time it corresponds to what is desirable for us.

Generally, standpoints determine the way of behaviour, they are consistent with behaviour if the situation allows that. Standpoints set the foundation for certain conative readiness, whose appearance in action depends upon situational conditions. In the cognitive part of standpoints, which is crucial condition for any performance, appear the ability and motivation of an individual.

\section{Requirements for a personality of safety manager}

Determination of personal prerequisites has to derive from specific activities performed on a position of a safety manager (in order to meet the framework of social-professional role of a safety manager) in specific institutions.

\subsection{The main activities carried out by a safety manager}

The main activities carried out by a safety manager are particularly:

- the creation of a concept and system of safety measures in institutions (plans, arrangements etc.) ;

- activities on prevention (precaution) and detecting of events jeopardising internal and external safety of institution, information safety;

- the analysis of threats, identifying risks, risky positions (cooperation with the HR department - tests of people on from safety point of view sensitive positions);

- controlling activity;

- investigation of extraordinary events (information leakage, system violation, material and financial damage etc.);

- proposal, introduction and implementation of adequate and timely, proactive measures;

- educational activity;

\subsection{Requirements for a personality of safety manager:}

- Abilities and motivation of individual we consider personal qualities to be crucial (abilities - shown as professional skills, social - dealing with people, motivating them, setting tasks, assessment etc. The motivation field also reflects values which an individual appreciates).

- As with any manager, the core of his activities is to deal with information. It includes the ability to obtain, process, analyse, use and protect information.

- In comparison with other managerial positions which involve dealing with information, it is the character and content of information, the way the information is obtained and how it is handled and used which makes the safety manager different.

Key skills are required for the work of safety manager, which have the following structure:

Social skills:

- Ability to work in team

- cooperation

- ability to face conflict situations

- communicativeness

Skills relating to the own person:

- competent dealing with himself, with his own value

- self-reflection

- purposeful development of own values of image

- ability to assess myself and to develop further 
Skills in the field of methods:

- systematically focus on targets by applying professional knowledge,

- form creative solutions,

- structure and classify new information,

- put things into context, learn about relations,

- critically review in order to achieve innovation,

- consider opportunities and risks.

Skills consist of different abilities and their mutual influencing. They are obtained in a reflexive way. In practice mainly the following abilities are required from a safety manager:

- Communication and cooperation - the ability to communicate and actively contribute in group processes in an original manner

- Problem solving and creativity is the ability to identify problems and solve them creatively.

- Independence and performance - the ability to independently plan, carry out and control the progress and results of work.

- Responsibility is the ability to accept joint liability.

- Thinking and learning is the ability to further develop the process of learning and thinking in connections.

- Line of reasoning and assessment is the ability to factually and critically assess the results of one's own, joint and other people's work.

These skills are not isolated from each other but create a harmonic whole.

\section{How to look for and select a safety manager}

The number of qualities of a safety manager is generally similar to required characteristics for a selection of an excellent and successful manager in any other field.

The US weekly Business Week evaluates the best and the worst managers of large international companies. Detailed analysis established the following criteria for determining the "longevity" of a safety manager, i.e. how long he can remain in his position and meet the interests of shareholders, not to fail their trust, reveal at least the following three and main criteria:

1. High IQ and emotional quotient;

2. Professional qualification

3. Long-term experience in managerial positions

Further essential criteria according to the US weekly are creativity and ability to bear great risk. It is an interesting fact that even on other positions we do not find the criteria of honesty.
Readers surely expect that when filling the post of a safety manager, a large number of specific principles must be observed. It is useful to bear in mind that the following principles for good personnel work with the following aspects mainly apply:

- The safety manager is selected as any other manager, i.e. we pay attention to the usual requirements for such position during selection.

- We consider aspects relating to specifics of his safety career history in our institution (company).

- The objectives, mission and position of an institution on society, the state or on the market, culture or inter-personal relations in a company etc. have an impact on safety policy in a company, and therefore on the setting of specific requirements and consequent selection criteria for the work of a safety manager. The criteria can be unique, different from any similar practice in other companies.

- The future place of a safety manager in the hierarchy of an organisation, the demands on him and the skills he possesses in order to meet the demands are also crucial.

- Great attention should be paid to the motivation of a safety manager. We cannot judge motivation only from the stand-point of recruitment - it should be monitored throughout the career. We should secure such conditions that the safety manager works loyally for the benefit of the institution, and we should also try to reduce personnel fluctuation, which represents a great risk from the safety point of view.

- We have to work with the safety manager, to motivate him, to give him space for personal development, allow career growth an overall satisfaction.

- It is recommended to carry out forensic audit (see further) with the aim to find all the risk factors of personnel characteristics.

- We have to bear in mind that sufficient time and finance has to be paid when selecting a safety manager. When filling a position of safety manager in a small organisation which is just starting to get involved in safety, one alternative is to recruit a person without the necessary safety knowledge and qualifications (while meeting the other required criteria), and subsequently securing his growth in the professional security field. When filling the position of safety manager in a large company it has to be a professional person with adequate experience, and it is essential to credibly assess the experience. It is common to check references, and in State institutions to perform operative safety tests, which can take months and are usually confidential. The effort costs a lot, therefore we have to be clear what tasks the safety manager will have in the institution.

\section{References:}

[1] MATOUŠKOVÁ, I., RAK, R.: The role of the safety manager when enforcing comprehensive information security, 5th International Conference Information Security Summit, 2004, pg. 85-98, Tate International, ISBN 80-86813-00-2

[2] MATOUŠKOVÁ, I.: Psychology and tactics of security investments driving in business sphere (in Czech), Security Magazín, č. 4/2004, pp. 48-49 
[3] RAK, R., MATOUŠKOVÁ, I.: Creative barriers, part I. - Security, human intellect and influence of social environment (in Czech), DSM 3/2004, pp. 26-28, Tate International, Praha

[4] RAK, R., MATOUŠKOVÁ, I.: Creative barriers, part II. - Security, emotion and interpersonal communication (in Czech), DSM 4/2004, pp. 28-30, Tate International, Praha

[5] RAK, R.: Homo sapiens as the most powerful and fragile segment for retrieving and securing of information (in Czech), DSM 4/2002, pp. 10-13, Tate International, Praha

[6] BRABEC, F. et al.: Safety for a company, institution, citizen (in Czech), Public History: 2001, ISBN 80-86445-04-06

[7] ČÍRTKOVÁ, L.: Criminal psychology (in Czech), Praha: Eurounion, 1998, ISBN 80-85858-70-3

[8] HALL, C., S., LINDZEY, G.: Psychology of personality (in Slovak), Bratislava: Slovenské pedagogické nakladatelstvo, 2002. ISBN 80-08-03384-3

[9] JANÍČEK, P., ONDRÁČEK, E.: Problems solving via modelling (in Czech), Brno, Vysoké učení technické, 1998, ISBN 80-214$1233-\mathrm{X}$

[10] KOHOUTEK, R., ŠTĚPANÍK, J.: Psychology of work and management (in Czech), Brno: Akademické nakladatelství CERM, 1999, ISBN 80-214-1552-5

[11] KULAJOVÁ, T., HALOUZKA, J., SEIGE, V.: Genesis or How safety department is created (in Czech), DSM, No. 2, 2001, pp. 32-35

[12] MIKULÁŠTíK, M.: Communication skills in practice (in Czech), Praha: Grada, 2003, ISBN 80-247-0650-4

[13] MITNICK, K., SIMON, W.: The Art of Deception: Controlling the Human Element of Security (in Czech - translate from English original), Praha, HELION S.A., 2003, ISBN 83-7361-210-6

[14] SPURNÝ, J.: Psychology of interrogation (in Czech), Praha: Portál, 2003, p. 114, ISBN 80-7178-846-5

[15] Analysis of information safety in the Czech Republic 2003 (in Czech), Praha, Ernst \& Young, DSM, NBÚ, 2003, ISBN 80-902858-8-0

[16] MATYAS, V., RAK, R., RIHA, Z.: Biometric Authentication - Trends and Vision, Information Security Summit 2002, pp. 66-90, Prague, ISBN 80-902858-5-6

[17] PORADA, V., NEČAS, S.: Bank security as the part of institution security policy (in Czech). Bezpečnostní teorie a praxe, zvl. číslo, Praha: PA ČR, 2001, p. 437-448. 